\title{
NOÇÕES INTRODUTÓRIAS AO DIREITO AGRÁRIO
}

\author{
Fábio Maria De-Mattia
}

Professor Titular de Direito Agrário da Faculdade de Direito da USP

\begin{abstract}
Resumo:
O Direito Agrário é formado por institutos que não possuem princípios legais gerais, porque estes não têm afinidade com todos eles. É possivel identificar princípios gerais comuns somente em alguns institutos agrários, mas não em todos. O Direito Agrário é uma especialidade dentre os diversos ramos do Direito.
\end{abstract}

\begin{abstract}
:
Agrarian Law is constructed by institutes no by legal general principles because these don't integrate all its institutes. It's possible to identify common general principles only in some legal agrarian institutes but not in all of them. Agrarian Law is a speciality appearing among the Law several branches.
\end{abstract}

\section{Capítulo I}

\section{INSTITUTOS, PRINCÍPIOS GERAIS E ESPECIFICIDADE}

O estudo da noção de instituto jurídico nos interessa porque através dele podemos encontrar o fundamento do "sistema na conexão orgânica dos institutos jurídicos" e a justificativa para a especificidade do Direito Agrário.'

Os institutos jurídicos devem ser considerados como "criações plásticas que representam a condensação de determinados conteúdos espirituais do direito e, em igual medida, fragmentos da realidade econômica e social. "2

Tais institutos constituem o material necessário para a construção do Direito Agrário como sistema, não como mero resultado da livre criação do legislador, mas sim caracterizando-se como elementos preexistentes ao próprio sistema.

1. Antonio Carrozza \& Ricardo Zeledón Zeledón, Teoria General e Institutos de Derecho Agrario, Buenos Aires, Astrea, 1990, p. 77.

2. Ibid., p. 78. 
Tal noção é verdadeira também para o Direito Agrário pois as normas que entram na composição de cada um dos institutos deste ramo do direito não podem perder de vista dados pré-constituídos, tais como as condições naturais do ambiente, os ciclos das estações do ano, as exigências da técnica relativas aos fatores e a organização da produção, as leis biológicas da criação animal ou vegetal etc. $^{3}$

Antonio Carrozza aponta que não tem um caráter necessariamente científico, senão somente técnico, o trabalho de reagrupamento e coordenação das disposições legais no contexto unitário dos institutos. A construção da teoria concernente aos institutos jurídicos é diferente pois, para o teórico, o instituto representa, num certo sentido, um ponto de partida, enquanto para os classificadores empiricos, como o legislador, um ponto de chegada. ${ }^{4}$

A individuação de eventuais princípios gerais passa, necessariamente, pelo trabalho prévio em torno dos diversos institutos formadores do Direito Agrário; o estudo comparativo dos mesmos pode levar a surgimento de princípios gerais.

Adolfo Gelsi Bidart pondera que, efetivamente, não é possivel determinar princípios gerais para só então desenvolver temas e questões neles fundados; pretensos princípios gerais e próprios da matéria só poderão surgir do estudo dos vários institutos e do confronto entre eles. ${ }^{5}$

Bidart, por exemplo, em consonância com o disposto por este método de abordagem e partindo do aspecto por ele considerado núcleo do Direito Agrário qual seja a atividade de exploração natural, destinada à obtenção de produtos bionaturais, vegetais ou animais - considera possível a identificação de elementos especiais e próprios a esta matéria, por meio dos quais poderão ser deduzidos os almejados princípios e os critérios gerais de ordenamento da disciplina, os mesmos que já regulam os chamados institutos do Direito Agrário. ${ }^{6}$

Antonio Carrozza e Adolfo Gelsi Bidart entendem que o Direito Agrário constitui um sistema jurídico cujo contorno é ainda desprovido de forma e
3. Carroza \& Zeledón, ob. cict., p. 79.
4. Ibid., p. 80-1.
5. Il Problema della Individuazione del Diritto Agrario, Rivista di Diritto Agrario, v. 62, p. 77,
6. Ibid., p. 78 . 1983. 
o conteúdo se encontra, por causas diversas, em estado fluido. Daí o trabalho classificatório não poder ser considerado simplesmente como parte de um mero antecedente, distinto do repensamento e qualificação dos institutos com intenção científica, pois em tais casos aumenta a dificuldade de uma divisão do trabalho entre a tarefa técnica e a tarefa teórica. Com efeito, razão não há para que se considere a primeira atividade como menos meritória do que a segunda. ${ }^{?}$

A especificidade do Direito Agrário, seu contorno como ramo autônomo, o significado da importância sistemática dos seus institutos jurídicos e 0 problema específico de sua reconstrução científica levam a dois pressupostos básicos na lição, sempre autorizada, de Antonio Carrozza: a) a afirmação de um modo de ser e de operar autônomo do Direito Agrário pressupõe descobrir e dispor de um conjunto de institutos jurídicos atuais, próprios e exclusivos; b) resulta disto evidente que os atributos de pertenencia e de exclusividade referem-se não tanto aos princípios - como se costuma admitir - quanto aos institutos. ${ }^{8}$

Neste sentido, uma indagação que se pode fazer a partir de uma tal assertiva é se a indicação feita abrangeria igualmente os institutos criados pelo direito costumeiro, às vezes ainda não incorporados à legislação, pressupondo-se sempre ao se falar em direito costumeiro, além do costume propriamente dito, a própria jurisprudência como forma de costume erudito, na lição sempre autorizada de Rubens Limongi França. ${ }^{9}$

A afirmação da existência de tais princípios gerais informadores deste ramo do Direito representa a justificativa, para alguns autores, de uma já configurada autonomia jurídica do Direito Agrário.

Antonio Carrozza sustenta que o ramo do Direito denominado Direito Agrário tem sua especialidade justificada pela existência de institutos próprios e não como se admitiu, em princípios gerais.

Todavia, ainda que se vislumbre a possibilidade de uma futura consideração autônoma do Direito Agrário como ramo da ciência jurídica, muitas e, a nosso ver, mais autorizadas são as vozes que ainda entendem esta disciplina como

7. Ob. cit., p. 81 .

8. Ibid., p. 81-2.

9. Manual de Direito Civil, 3’ ed. rev., São Paulo, Revista dos Tribunais, 1975, v. 1, p. 23. Aliás a Rubens Limongi França devemos a opção pela expressão especificidade. 
apenas um ramo especial do Direito Privado, mais especificamente do Direito Civil, pelo exato problema da falta de determinação dos chamados princípios gerais.

Mario De Simone, por exemplo, afirma expressamente entender o Direito Agrário, sob o aspecto jurídico, como simples fração contida no Direito Civil, uma vez que no Direito Italiano a maior parte das normas relativas à matéria agrária estão contidas no Código Civil. Assim, uma vez inexistente a autonomia legislativa, impossivel seria poder formular, através de um procedimento de abstração, princípios gerais novos, próprios e especiais ao direito que se deseja ver autônomo. $^{10}$

Tal fato não impede, todavia e este também, é o nosso ponto de vista, que se reconheça a validade e a importância da autonomia didática e científica do Direito Agrário.

Não acarreta tal visão prejuízo, com efeito, à autonomia didática, que se justifica perfeitamente, tanto pelo aspecto da divisão e especialmente do estudo, como pela moderna ordenação que recebem as disciplinas universitárias; não atenua a autonomia científica, pois, segundo Mario De Simone, que reconhece a possibilidade de uma sistematização orgânica dos institutos, é perfeitamente possivel formar o objeto de um estudo científico autônomo para esta matéria, estudo que deve mesmo ser individualizado por imposição das razões técnicas dos próprios institutos.

Como se verifica, Mario De Simone se posiciona apontando para um prenúncio verdadeiro e real favorável à futura consideração autônoma do Direito Agrário, ainda por vir.

Nesta linha de raciocínio seguem outros juristas maiores, tais como Ettore Casadei, que verifica que a comprovação da existência de princípios gerais e próprios, distintos dos princípios de outros ramos jurídicos, é a condição necessária para que se possa reconhecer a autonomia de um determinado ramo do Direito. "

Assim sendo, sob uma tal condição, Ettore Casadei fundamenta com precisão que os princípios efetivamente próprios e pertinentes apenas ao Direito

10. Lineamenti di Diritto Agrario: parte generale, 5' ed., Napoli, Pellerano del Gaudio, 1970, p. 11.

11. Diritto Agrario, 1975, p. 13-4 (apostila utilizada pelos alunos da Faculdade de Jurisprudência da Universidade de Bologna e Modena). 
Agrário, não foram até aqui, convenientemente formulados pelos que afirmam a existência dos mesmos.

Ettore Casadei sustenta, contrariando até certo ponto as idéias de Antonio Carrozza e de Adolfo Gelsi Bidart sobre a caracterização dos institutos a partir da atividade agrária, que mesmo uma particular valoração normativa dos institutos próprios do Direito Agrário não bastaria, por si só, como fundamento suficiente para garantir a autonomia sistemática da matéria. Com efeito, fosse suficiente esta condição, chegar-se-ia por igual a uma pretensa e possível autonomia do Direito de Edificação ou então a uma outra, relativa ao Direito sobre bens corporais, e assim por diante.

Nem se diga, por outro lado, que a existência confirmada de alguns princípios jurídicos particulares à agricultura serviria de garantia para a pretensa individualização deste ramo do Direito. Ettore Casadei lembra, com perspicácia, o fato por exemplo de serem os princípios que regem os bens móveis próprios e característicos desta matéria, bastante diversos daqueles vigentes com relação aos bens imóveis; contudo, não há de se falar por isso de qualquer autonomia do Direito dos bens móveis em confronto com o dos bens imóveis.

Ettore Casadei reconhece a existência de institutos peculiares ao Direito Agrário, além da singularidade desta matéria especial. Destaca, igualmente, o fato de, até o momento, não terem a doutrina e tampouco a jurisprudência enunciado claramente os princípios gerais que, elevando à condição de um sistema o atual complexo de normas, poderiam atribuir organicidade à disciplina da atividade agrária. $^{12}$

Os princípios gerais podem surgir como elementos caracterizadores de um ou vários institutos de Direito Agrário, mas a especialidade comprova-se através dos institutos jurídicos.

Justifica sua diretriz ao asseverar que esta correção de rumos e de enfoque (dos princípios para os institutos) parece hoje impostergável.

Aponta ser suficiente verificar a frustração existente na esperança inerente à determinação dos princípios gerais e fundamentais da matéria. ${ }^{13}$

12. Ob. cit., p. 13-4.

13. Carrozza \& Zeledón, ob. cit., p. 81-2. Aponta como partidários de os princípios gerais justificarem a autonomia: Ageo Arcangeli, Il Diritto Agrario e la sua Autonomia, na introdução ao Curso de Direito Agrário ministrado na Universidade de Bologna no ano acadêmico 1927-1928, inserida em 
A crítica feita à existência de princípios gerais do Direito Agrário levou Antonio Carrozza a acolher a observação negativa manifestada pela doutrina mais prudente e autorizada, de acordo com a qual "de tais princípios, até o momento, e salvo erro, não se formulou nenhum"

E conclui que à falta de objetivação e de individuação destes princípios gerais por parte da doutrina e jurisprudência, observou-se que 0 importante não são eles mesmos, senão a capacidade potencial da matéria de produzi-los. ${ }^{14}$

Antonio Carrozza pondera que tal capacidade conserva o caráter de simples hipótese, já que se nada pode demonstrar a existência de princípios gerais (melhor generalíssimos, pelo grau de abstração com que a eles se aludia), é razoável duvidar de que efetivamente tal capacidade exista.

Afasta a relevância atribuída aos princípios gerais argumentando que, por outro lado, não se compreende porque os estudiosos de um direito especial, como o agrário, devem estar e se sentir obrigados a semelhante tipo de demonstração, quando está provado historicamente a extrema dificuldade de circunscrever e, inclusive, de enumerar princípios gerais que regem setores normativos que gozam de uma autonomia consolidada e indiscutida. ${ }^{15}$

Nesta linha de idéias Antonio Carrozza aponta que a história do pensamento jurídico deveria ensinar que também no caso dos ramos maiores do ordenamento não foram tanto os princípios gerais quanto seus produtos normativos (tanto de primeiro grau: normas; como de segundo grau: institutos), que considerados pertinentes a um determinado ramo do direito e típicos dele, constituem a manifestação mais convincente da autonomia conseguida. ${ }^{16}$

Carrozza entende dever ser o primeiro passo a determinação prévia dos princípios informadores de cada instituto para, em seguida, detectar princípios especiais, peculiares ao Direito Agrário, porém suficientemente gerais para operar no âmbito total deste ramo do Direito.

Scritti di Diritto Commerciale e Agrario, v. 3, p. 340; Giovanni Carrara, Corso di Diritto Agrario, 2 ed., t. 1, p. 15 e ss.; Enrico Bassanelli, Corso di Diritto Agrario, p. 20-1.

14. Ibid., p. 82-3.

15. Ibid., p. 83 .

16. Ibid., p. 84. 
Com efeito, é através das unidades elementares de agrupação das normas jurídicas, unidades que são precisamente os institutos, que se poderá alcançar o reconhecimento das estruturas necessárias para a reconstrução teórica do ordenamento. $^{17}$

Carrozza defende a especificidade do Direito Agrário através dos institutos jurídicos e não dos princípios gerais e defende a utilidade do método proposto.

Agustin Luna Serrano, por igual, verificando inexistir até o presente momento uma enunciação satisfatória dos pretendidos princípios gerais de Direito Agrário, formulou sua posição de forma bastante expressiva, frontalmente crítica à idéia de autonomia da matéria com base na existência de tais princípios.

Luna Serrano informa que a existência eventual destes princípios tem sido afirmada por vários agraristas e verifica, contudo, que os autores que abordam o tema têm se negado a indicar quais sejam estes, em concreto. ${ }^{18}$

O eminente jusagrarista espanhol cita, neste sentido, a enunciação dos princípios gerais da matéria intentada por Carlo Frassoldati, que indica como tais a boa exploração ou bom cultivo, a dimensão mínima da empresa agrária, a não cindibilidade dos resultados conjuntos do ano agrícola, a colaboração nos contratos agrários e a colaboração entre fundos. ${ }^{19}$

Luna Serrano aponta, com absoluta precisão, que enunciações como esta parecem derivar muito mais da natureza das coisas, ou seja, de meros dados, naturais e técnicos, e não daqueles considerados propriamente jurídicos.

Ainda que se admitisse que os princípios até hoje apresentados tivessem a natureza de verdadeiros princípios jurídicos, todavia seriam ainda demasiado gerais, atendendo ao aspecto global da ciência jurídica e não a peculiaridade do ramo especial que é o Direito Agrário.

Luna Serrano parte do entendimento de que o Direito Agrário regula a atividade profissional dos agricultores e, estruturada a disciplina sobre a exploração da terra, compreende-se o posicionamento do autor de ser o Direito

17. Ob. cit., p. 84. Consultar, também, Ettore Casadei, ob. cit., p. 14.

18. La Formación Dogmatica del Concepto de Derecho Agrario. In Rivista di Diritto Agrario, v. 51 , n. 1, p. 513, 1972.

19. Ibid., p. 513. 
Agrário um ramo especializado do Direito Privado, mais particularmente do Direito Civil. $^{20}$

Assim, a essência civilista das instituições que formam o conteúdo material básico do Direito Agrário estaria atendida, não se impedindo, não obstante, a incidência sobre estas instituições de normas limitadoras, provenientes do Direito Público. ${ }^{21}$

Alberto Ballarin Marcial, também outro expoente da escola agrarista espanhola, após haver buscado sem melhores resultados a definição dos princípios gerais da matéria, acabou igualmente por afirmar que os supostos princípios gerais do Direito Agrário, até o momento apresentados, são ou demasiado amplos para serem, unicamente, peculiares ao Direito Agrário ou demasiado estreitos para que possam ser considerados comuns à totalidade de seus institutos.

Ballarin Marcial reconhece, adotando integralmente as idéias sugeridas por Luna Serrano, que os enunciados que recebem a denominação de princípios são na realidade as metas e os objetivos finais que buscam alcançar as normas jurídico-agrárias. ${ }^{22}$

Carrozza ressalta que a validade da tese de que o Direito Agrário seja estudado por institutos - os quais são o ponto de partida para toda afirmação de autonomia ou simplesmente de especialidade - não se reduz pela verificação eventual de um número não relevante, ou até escasso, de institutos sobre os quais operar, posto que este fenômeno pode se explicar não apenas pelo fato, extremamente óbvio, de que os meios são escassos porque são poucos os que nele trabalham, senão até pela falta de integridade e completude que ainda afeta o direito agrário positivo. ${ }^{23}$

Carrozza exemplifica seu pensamento a respeito do desenvolvimento retardado na elaboração dos institutos com o direito sucessório ou hereditário, o qual, se comparado com alguns ordenamentos, especialmente dos países germânicos, adquiriu notável nível de especialidade ao não ser considerado como

20 . Ob. cit., p. 514.

21. Ibid., p. 514.

22. Derecho Agrario, $2^{\star}$ ed., Madrid, Editorial Revista de Derecho Privado, 1978, p. 594-5.

23. Ob. cit., p. 84-5. 
simples parte do Direito Civil, diferentemente com o que ocorre em inúmeros sistemas jurídicos de Direito Agrário de outros países europeus. ${ }^{24}$

Carrozza conclui defendendo a validade do método em exame e considera que ele não se deteriora pela verificação da instabilidade dos institutos jurídicos de Direito Agrário, asseverando que não há dúvida que a mutação contínua e freqüente dos fatores políticos, econômicos e tecnológicos motiva alterações quantitativas ou qualitativas sem pausa no conteúdo do Direito Agrário. $^{25}$

Ricardo Zeledón Zeledón aponta que o grande esforço na formulação de princípios gerais com caráter de fundamentais e ordenadores de toda a normativa do Direito Agrário não foi bem-sucedida, por eles não terem sido devidamente identificados. ${ }^{26}$

Exemplifica com institutos de Direito Agrário que se desagregaram: a) a proibição dos atos de emulação era um critério que determinara a esfera da atuação lícita em matéria de atividade fundiário-agrária; b) por muito tempo, a distinção entre servidões rústicas e urbanas foi algo mais do que uma mera distinção terminológica tal como é hoje; c) no campo do direito contratual, figuras novas se acrescem, sem pausa, às antigas, e muitas destas últimas desapareceram, talvez para reaparecer mais tarde; d) sintomática é a decadência progressiva do destino das relações associativas agrárias e da parceria clássica em particular. Não há perigo de erro observando-se a esse respeito que o fenômeno não é exclusivamente italiano ou europeu; e) o estudioso de história jurídica agrária está habituado a fenômenos de sobrevivência extralegal e inclusive, contra legem, assim como a fenômenos de revivescência; f) particularmente neste último setor, a redução forçada ope legis das relações contratuais agrárias em um numerus clausus, a conversão legal de um tipo em outro nos contratos agrários e a contração da área de sobrevivência da autonomia negocial dos particulares poderiam ser interpretadas como sinais de um empobrecimento progressivo do conteúdo típico do Direito Agrário, já exposto ao perigo do processo econômico que implica a chamada industrialização das formas clássicas do exercício da empresa agrária.

24 Ob. cit., p. 85 .

25. Ibid., p. 85-6.

26. Ibid., p. 60. 
Antonio Carrozza aponta que os princípios gerais hão de se encontrar, devendo ser estritamente positivos, mas mais adequado seria estudar o Direito Agrário por institutos, buscando outros tipos de princípios, menos universais e gerais, porém mais profundos, que poderiam estruturar um sistema ao permitir ubicar os institutos de maior ou menor categoria, determinando se pertencem ou não ao Direito Agrário.

Ricardo Zeledón Zeledón assevera que, com esta proposta, não apenas se oferece uma saída científica e metodológica mais clara, mas principalmente, se desmistifica o problema dos princípios gerais.

Conclui que Carrozza demonstrou que o tema dos princípios gerais do Direito Agrário é um problema falso pelo menos como proposto por Arcangeli

e que convém dirigir todos os esforços por caminhos que permitam vislumbrar uma conclusão segura não pela via dos princípios, pois quem se aventurou nela não alcançou um lugar seguro, porém encontrou-se cada vez mais perdido.

Waldírio Bulgarelli, comentando o capítulo da empresa no Projeto de Código Civil, conclui que "a agrariedade conta com um suporte legal quase completo (contratos, crédito e titulos de crédito) com dimensões e amplitude de um verdadeiro sistema próprio". Isto revela a importância que atribui aos institutos para a criação de um sistema especial. ${ }^{27}$

\section{Capítulo II}

\section{ESPECIFICIDADE DO DIREITO AGRÁRIO}

A doutrina representativa dos diversos países onde o Direito Agrário encontra hoje o seu maior desenvolvimento, ainda que analisando a matéria sob as mais variáveis perspectivas e argumentos, não se divide radicalmente ao reconhecer as particularidades que caracterizam o Direito Agrário.

Guy Chesne e Edmond-Noel Martine, juristas da escola agrarista francesa, entendem, por exemplo, que a afirmação do particularismo do Direito Agrário está ligada às funções que o Estado atualmente exerce na vida econômica e

27. A Teoria Juridica da Empresa: Análise Juridica da Empresarialidade, São Paulo, 1984, p. 431. 
social, destacando que no setor agrícola esta intervenção se manifesta principalmente a partir do final do século passado, continuando sem solução de continuidade até os dias de hoje. ${ }^{28}$

Louis Lorvellec, por sua vez, destaca que a avaliação destas peculiaridades é por demais variável, devendo ser identificada através de uma comparação pormenorizada entre os ordenamentos jurídicos dos diversos paises $\mathrm{e}$ de período a período. Por exemplo, no momento atual, o autor identifica a disciplina do Direito Agrário na França como um ramo destacado do Direito Civil e em oposição ao Direito Comercial, constituindo-se, em suma, no Direito de uma categoria social, de uma política econômica especializada e de uma zona particular de território. ${ }^{29}$

A melhor orientação da escola agrária francesa, contudo, parece ser aquela liderada por Jean Megret, que lucidamente destaca as particulares características que qualificam o Direito Agrário, reconhecendo que as mesmas são todavia insuficientes para conceder a esta matéria o traço de autonomia absoluta, como querem alguns. ${ }^{30}$

Já a moderna escola agrarista italiana, representada, sobretudo, por Antonio Carrozza ensina que na base da especificidade do Direito Agrário encontra-se, sempre, a idéia da possibilidade teórica e da conveniência prática de separar a matéria fundiária, que corresponde ao Direito Civil, e a matéria agrária propriamente dita. $^{31}$

Para Ricardo Zeledón Zeledón, a especificidade do Direito Agrário é objeto de uma corrente que considera o agrário e o Direito Agrário ainda imerso dentro do "tronco comum do direito civil", reconhecendo-lhe particularidades concretas em suas normas, o que a faz suscetível de um tratamento jurídico especifico. ${ }^{32}$

28. Droit Rural, Paris, Dalloz, 1986, p. 3.

29. Droit Rural, Paris, Masson, 1988, p. 2 e ss.

30. Droit Agraire, Paris, Librairies Techniques, 1973, t. 1, p. 13.

31. Ob. cit., p. 83.

32. Jbid., p. 42. 
Zeledón Zeledón aponta que a tese da especificidade adquiriu força por causa da falta de consenso na existência de princípios gerais próprios e exclusivos. ${ }^{33}$

O termo especificidade do Direito Agrário não será por nós utilizado no sentido de contrapor a escola jurídica de Ageo Arcangeli frente à escola técnica de Giangastone Bolla, pois o primeiro sustentou a especialidade e o segundo a autonomia.

A especificidade do Direito Agrário atenta para a particularidade de no seu interior (parte interna do Direito Agrário) existir uma coordenação entre normas de direito privado e de direito público e, por conseqüência, seus institutos submetem-se a esta dupla influência.

As normas agrárias revelam certa singularidade e particularidade, não só as normas privadas ou só as públicas, senão de modo melhor as normas públicas e privadas. ${ }^{34}$

Verifica-se que esta posição converge em muito com aquela sustentada pelo renomado agrarista Fernando Pereira Sodero que, no seu conceito de Direito Agrário, concebido como o "conjunto de principios e de normas, de Direito Público e de Direito Privado, que visa a disciplinar as relações emergentes da atividade rural, com base na função social da propriedade da terra" ressaltava a sua idéia de coordenação das normas públicas e privadas na configuração dos institutos. ${ }^{35}$

Ricardo Zeledón Zeledón considera que a especialidade refere-se às normas que têm esse atributo em virtude de regular situações jurídicas totalmente diferentes dos demais corpos normativos, independentemente se essa especialidade acontece por normatizar um fato técnico especifico, uma relação particular ou, enfim, interesses de natureza diferente. ${ }^{36}$

Ensina que a especialidade das normas agrárias provém da incapacidade do Código Civil regular aspectos concretos do processo econômico. Primeiro, através da legislação especial, o ordenamento jurídico começa a receber influxo de grande quantidade de normas que - na visão dos civilistas clássicos -

33. Ob. cit., p. 47.

34. Ibid., p. 50.

35 . Direito Agrário e Reforma Agrária, São Paulo, Livraria Legislação Brasileira, 1968, p. 32.

36. Ob. cit., p. 67. 
assumem o caráter de normas excepcionais, ou seja, esclarecem, adicionam ou interpretam a lex generalis. Assim começa a aparecer um direito especial, ao qual se observa exclusivamente como Direito Civil promulgado fora do Código Civil; mais tarde, esse acúmulo de normas sem sistema próprio começa a ter uma certa lógica interna, um critério integrativo, com o que se chega à etapa da legislação agrária, cujo destino é se converter em Direito Agrário, totalmente separado do tronco comum. ${ }^{37}$

Neste sentido deve ficar evidenciada a posição dos institutos. Estudar o Direito Agrário por institutos obriga necessariamente o cientista a reagrupar normas dispersas no ordenamento jurídico não necessariamente coincidentes num mesmo corpo ou em um momento histórico determinado - e qualificá-las institucionalmente. Logo após ocorrerá - como assinala Carrozza - a extrapolação destes princípios, talvez não tão gerais e universais, porém mais concretos e profundos. $^{38}$

O trabalho, então, se inicia na base mesma do ordenamento jurídico, ainda que posteriormente deva se realizar uma abstração. $O$ erro se radicaria ao estabelecer a abstração sem uma referência direta a essa normativa com caráter de especificidade, tal como sucedeu com alguns juristas que intuíram, porém não demonstraram, a existência do Direito Agrário. ${ }^{39}$

A utilização do método de estudo por institutos pode, também, ajudar a determinar mais facilmente a existência da especificidade, assim como o grau alcançado por ela, constituindo um critério próprio da moderna escola de Direito Agrário. $^{40}$

Luigi Costato, tendo presente normas comunitárias e constitucionais de Direito Agrário na Itália, analisa a matéria de modo a enquadrá-lo como partidário da especificidade, a qual se caracteriza pelo conteúdo das normas ditas agrárias.

Assevera que as matrizes do Direito Agrário encontram-se na relevância que apresenta o momento da atividade em confronto com o momento da fruição do bem produtivo; a peculiaridade de tratamento do momento da atividade

37 . Ob. cit, p. 67-8.

38. Ibid., p. 68.

39. Ibidem.

40. Ibidem. 
não pode prescindir da importância deste segundo momento como emerge, também, da regra constitucional. ${ }^{41}$

Disto derivou uma dicotomia pela qual, por um lado, a valorização da empresa e dos bens por ela produzidos para o mercado consentiu especificar um Direito Agrário onde as regras consuetudinárias foram logo subjugadas por aquelas desejadas pelo legislador; por outro lado, os modos de fruição e de aquisição do bem-terra penetraram no Direito Agrário, através do mesmo vínculo que liga - em certos aspectos - o terreno (e os animais) à atividade empresarial agrária, elementos estes que, em parte e ao invés, ficaram incorporados no direito privado, pois que outras vezes o dado normativo não atribui relevância particular ao liame terra (ou animais) - empresa agrícola. ${ }^{42}$

Luigi Costato vê disto decorrer a distinção que entende poder se confirmar entre direito da agricultura e direito sinteticamente dito agrário, no primeiro estando compreendidas normas não tipificadas pela sua agrariedade ainda se relativas a bens que o próprio empresário agrícola pode utilizar e gozar - e não especificamente ditadas em relação à existência de uma empresa que utilize as normas, das quais não se ocupou o eminente autor a não ser para algumas chamadas. ${ }^{43}$

Costato define o Direito Agrário como o complexo de normas que regulam a atividade empresarial agrícola, ainda que tais regras não sejam ditadas, freqüentemente, de modo exclusivo para a empresa, abrangendo também em matérias assaz relevantes, atividades não-empresariais ou não-agrárias. Neste sentido, constitui exemplo aquele apresentado pelos contratos agrários, entre os quais se especificam hipóteses de concessão para o não empreendedor agrícola; e as normas comunitárias sobre intervenção no mercado de produtos agrícolas, que de um lado se podem referir a produtos assim denominados de primeira transformação industrial (açúcar, insulina, etc.), e de outro lado são aplicadas a todos os detentores e não-somente aos empresários agrícolas (como os preços de intervenção estabelecidos pelo governo). ${ }^{44}$

41. Compendio di Diritto Agrario Italiano e Comunitario, Padova, CEDAM, 1989, p. 20.

42. Ibid., p. 20.

43. Ibidem.

44. Ibid., p. 21. 
Estas extensões quanto à eficácia são impostas para tutelar o diretamente empresário agrícola e o seu estabelecimento; na realidade, o fato de as regras da concessão de uso de terreno agrícola se aplicarem, também, a não empresários parece ser não tanto fruto de uma distração do legislador, mas antes uma técnica para evitar formas de concessão de uso de terreno agrário subtraídas ao regime especial, através das quais a parte concedente poderia efetuar negócios, também, com empresários agrícolas, aperfeiçoados em modo contrário ao interesse que a lei pretende tutelar.

Dá mesma forma, o sistema de preços dos produtos agrícolas foi posto em prática sem individualizar especificamente os sujeitos protegidos, mas em verdade com o escopo de tutelar os rendimentos dos empresários agrícolas, que se efetua com a intervenção sobre produtos não agrícolas, ligados aos primeiros (empresários agrícolas) na relação produto-transformando-produto agrícola para ser transformado ou produto sucedâneo produto agrícola. ${ }^{45}$

Fernando Salaris ressalta que em doutrina observou-se que o fato técnico constitui um dos fatores de especificação do Direito Agrário, idôneo a incidir sobre a especialidade da matéria com uma estruturação adequada dos preceitos. $\mathrm{O}$ fato técnico está presente em toda manifestação típica que transforma o Direito Agrário em um jus, que se adiciona à substância regulada e de tal substância pode-se dizer proprium. A técnica da complementação do dispositivo legal com referência ao fato técnico realiza, indiretamente, a adequação do direito à natureza do fato a regular, evidencia os motivos de natureza sócio-política das escolhas não apenas legislativas, mas interpretativas. ${ }^{46}$

45 . Ob. cit., p. 21.

46. La Riduzione al "Tipo Unico" dei Contratti Agrari, Torino, G. Giappichelli, 1989, p. 80 - Cita Carrozza, Problemi Generali e Profili di Qualificazione del Diritto Agrario, p. 108 e ss. 